\title{
OLHARES SUBJETIVOS PARA A ALFABETIZAÇÃO
}

\author{
SUBJECTIVE VIEWS ON LITERACY
}

Francisco Renato LIMA

Universidade Federal do Piauí fcorenatolima@hotmail.com

\author{
Maria Angélica Freire de CARVALHO \\ Universidade Federal do Piauí \\ angelifreire@oi.com.br
}

\begin{abstract}
Resumo: A reflexão apresentada nesse estudo parte da necessidade de aproximar o processo de aprendizado da leitura e da escrita - etapa formalmente estabelecida pela escola como alfabetização - e aspectos subjetivos da linguagem, nos quais se inclui a percepção do homem como sujeito de si, em sua historicidade, por meio da aquisição da língua escrita. Nessa percepção, esse fato acarreta uma mudança identitária, pragmática e sociocultural do sujeito que, imerso em uma pluralidade de vivências e de experiências de vida - letramentos sociais - singulariza-se e dá significado ao mundo por meio de resquícios de escrita. A demonstração desse aspecto parte de uma pesquisa bibliográfica e exploratória, de abordagem qualitativa e dialógica, evidenciando que a intervenção sobre o tema será apenas de caráter teórico-filosófico, ainda que, construída sob experiências empíricas vivenciadas pelo pesquisador, no exercício da docência e no trabalho pedagógico com o ensino da língua em sala de aula. Um olhar subjetivo para a alfabetização permite compreendêla, portanto, como etapa básica e fundamental na formação do indivíduo, que assume uma autoria, discursivamente e socialmente, por meio da linguagem; de tal modo, perceber os meandros e as interfaces subjetivas, que permeiam essa fase de aprendizagem, é agregar valores humanos, conceituais e atitudinais para a melhoria das práticas de ensino.
\end{abstract}

Palavras-chave: Aprendizagem. Alfabetização. Subjetividade. Leitura. Escrita.

\begin{abstract}
The reflection presented in this study starts from the need to approximate the learning process of reading and writing - a stage formally established by the school as literacy - and subjective aspects of language, which include the perception of man as subject of himself in his historicity, through the acquisition of written language. In this perception, this fact leads to an identity, pragmatic and sociocultural change of the subject, which immerses itself in a plurality of experiences and experiences of life social literatures - singles out and gives meaning to the world through remnants of writing. The demonstration of this aspect is part of a bibliographical and exploratory research, with a qualitative and dialogical approach, evidencing that the intervention on the subject will only be of theoretical-philosophical character, although, constructed under empirical experiments experienced by the researcher, in the teaching and in the pedagogical work with the teaching of language in the classroom. A subjective view of
\end{abstract}


literacy makes it possible to understand it as a basic and fundamental step in the formation of the individual, which takes on authorship, discursively and socially, through language; in order to understand the meanders and the subjective interfaces that permeate this learning phase, is to aggregate human, conceptual and attitudinal values for the improvement of teaching practices.

Keywords: Learning. Literacy. Subjectivity. Reading. Writing

\section{Introdução}

Para além dos currículos cristalizados, o processo de alfabetização urge por uma discussão que entrelace saberes e fazeres, significados e sentidos como movimentos de rupturas a resistências em perspectivas tradicionalmente prescritas; considerandose, hoje, as especificidades de organização dos tempos e espaços de aprendizagem, assim como de circulação da leitura e da escrita na vida cotidiana, a qual está estruturada a partir de uma tessitura textual (oral e escrita) que possibilita uma organização discursiva do mundo.

Dentro desse contexto, o paradigma newtoniano-cartesiano, impregnado nas práticas educativas, demarcado pela lógica do conservadorismo, reprodução do conhecimento e limitação do poder de criatividade dos alunos, perde lugar para as abordagens sistêmicas, holísticas e progressistas do ensino e aprendizagem, nas quais o afã da discussão e da abordagem prática de ensino valoriza as práticas sociais, em que o sujeito traz para a escola aquilo que vivencia em seu cotidiano e, ao entrar em contato com o conhecimento formal, amplia suas percepções de mundo, modifica suas ações e possibilita a construção de uma identidade social.

O esforço em construir um discurso teórico-prático acerca dos aspectos subjetivos da alfabetização tem por base desmontar práticas historicamente arraigadas nessa etapa de formação do indivíduo e legitimar novos modos de pensar e fazê-la, a partir da justaposição entre aspectos cognitivos, subjetivos, intelectuais, culturais, sociointerativos e temporais que se articulam na fase de alfabetização da criança.

A interface entre alfabetização e subjetividade compreende o processo de aquisição da língua escrita como uma mudança identitária, pragmática, portanto, social do sujeito, a qual compreende uma pluralidade de vivências que o singularizam e dão significado na construção de si. Com a leitura de textos e suas entrelinhas, o sujeito estabelece pontes de entrada e saída no e do "confinamento da subjetividade, 
do silêncio" (SANTIAGO, 2005, p. 42) rumo a uma ampliação da visão de mundo e da inserção crítica e emancipada para o exercício da democracia.

A aprendizagem, sob essa perspectiva, é considerada como um processo subjetivo e de natureza social, no qual o conhecimento realiza-se por meio da articulação entre os aspectos subjetivos da criança, que são intrínsecos ao sujeito, e as configurações da subjetividade social, que segundo a Teoria da Subjetividade de González Rey (2003, p. 205-206), tem sido definida como "[...] o resultado de processos de significação e sentido que caracterizam todos os cenários de constituição da vida social, e que delimitam e sustentam os espaços sociais em que vivem os indivíduos", compreendendo-se, assim, as instâncias do ler e do escrever, seja na escola ou nos demais contextos de aprendizagem nos quais o sujeito circula.

Analisar os aspectos subjetivos inerentes à fase de alfabetização da criança, com foco nas práticas pedagógicas, que potencializam uma aprendizagem significativa da leitura e da escrita, é o objetivo deste estudo, que se organiza a partir dos achados da pesquisa bibliográfica e exploratória, de caráter qualitativo e dialógica, com base em parâmetros epistemológicos, culturais e sociais, que auxiliam na construção de sentidos para um texto. Na literatura pertinente, busca-se o apoio teórico em leituras conciliáveis entre Bakhtin (2009/2011), Benveniste (2005/2006), Ferreiro; Teberosky (1999), Freire (2011), González Rey (2003), Piaget (1953), Soares (2005), Smolka (2008), Vygotsky (2000), entre outros.

O raciocínio desta escrita parte de uma abordagem pedagógica, conjugada ao ponto de vista linguístico, buscando elucidar questões que se colocam no plano teórico-epistemológico acerca da alfabetização, enquanto processo de (des) construção do sujeito, mediante a compreensão das relações entre leitura e escrita. Investiga-se a escola como lugar de contato para a produção desta escrita; acompanhando as práticas de ensino e refletindo sobre a formação docente para o exercício das primeiras letras, com vistas ao letramento.

\section{Alfabetização: palavras de subjetividade}

A apropriação da escrita inscreve sentidos na existência humana, pois estar inserido no mundo alfabético representa uma abertura para um vir-a-ser, projetando 
uma inserção e independência intelectual, visto que "quando aprendemos a ler [...] novas perspectivas se abrem para nós. Este mundo, o mundo da vida comum, tornase, uma vez mais, investido de alma, misteriosamente interconectado, significativo e fascinante" (JONHSON; RUHL, 2010, p. 111). Sob esta perspectiva, a alfabetização produz nos sujeitos uma conexão social, altera seu status quo e os motiva a reconstruírem-se no meio que os cercam; tal como o dito filosófico: "Conhece-te a ti mesmo e conhecerás o universo" (Sócrates).

A alfabetização representa uma mudança atitudinal e processual no nível da linguagem: porque se passa da fala assistemática, na qual o indivíduo ainda não tem o conhecimento do sistema alfabético e a capacidade de codificar e decodificar os signos linguísticos, reconhecendo-os através de sons (fonemas) e reproduzindo-os na escrita (grafema); e passa a uma organização sistêmica da língua, com base na sua estrutura e funcionamento interno, visto que a língua é um sistema de natureza social, político e cultural, que tem na fala a sua legítima expressão.

No processo de apropriação da linguagem escrita, o sujeito sintetiza, formula e reorganiza as relações subjetivas no processo de construção de sentidos, considerando que a linguagem, segundo Benveniste (2006, p. 87) é própria ação da subjetividade, marcada no mundo pela enunciação, que se caracteriza pela "acentuação da relação discursiva com o parceiro, seja este real ou imaginário, individual ou coletivo".

Das implicaturas teóricas às práticas, a alfabetização consiste, pois, em reinventar a linguagem, a experiência, o vivido, buscando através da subjetividade, desafiar a criança a crescer, a ir além das evidências, que se apresentam em seu contexto, e levando-a a situações imaginárias presentes nos textos e, deste modo, contextualizando e refletindo sobre o objeto cognoscível, através de três faces subjacentes à apropriação da linguagem: a fala, a escrita e a leitura. Esses três elementos operam de forma interdependente no processo de organização funcional da linguagem e da comunicação humana.

A fala é a primeira dessas etapas de expressão do pensamento e se manifesta nas situações do dia a dia, dentro e fora da escola, realiza-se quando a criança adquire o significado da palavra, entendendo-a na sua na relação com algo que ela observa 
ou experimenta, ou seja, a criança compreende a relação entre palavra e objeto designável, e os identifica separadamente.

Ao entrar na escola, espera-se que a criança já tenha domínio sobre a compreensão e expressão da palavra falada para que, durante a sua fase de alfabetização, ela esteja apta a alcançar as etapas superiores no domínio da linguagem: a leitura e a escrita.

Os domínios da escrita e da leitura atendem a um desenvolvimento diferenciado do ocorrido na fala; pois, apesar de serem processos relacionados à fala, eles têm suas especificidades e exigem uma proposta diferenciada, durante o processo educativo, para que haja a sua apropriação e desenvolvimento com eficiência. Lacerda (1995) corrobora que a habilidade de falar bem é muito importante para o bom desenvolvimento da criança durante o aprendizado da linguagem escrita.

Deste modo, Lajonquière (2010, p. 2) destaca que "educar é endereçar a palavra a uma criança"; e, mediante essa compreensão, é salutar o zelo nesta intermediação, conforme salienta Bakhtin (2009, p. 42-117), em vista de que:

[...] a palavra será sempre o indicador mais sensível de todas as transformações sociais, mesmo daquelas que apenas despontam, que ainda não tomaram forma, que ainda não abriram caminho para sistemas ideológicos estruturados e bem formados. (BAKHTIN M., 1999, p. 41)

Ela é determinada tanto pelo fato de que precede de alguém, como pelo fato de que se dirige para alguém. Ela constitui justamente o produto da interação do locutor e do ouvinte. (BAKHTIN M., 1997, p. 117)

Toda palavra serve de expressão a um em relação ao outro. Através da palavra, defino-me em relação ao outro, isto é, em última análise, em relação à coletividade [...] A palavra é território comum do locutor e do interlocutor. (VOLOSHINOV V., 2006, p. 117)

Para essa compreensão, recorre-se também a Vygotsky (2000, p. 125), que em diálogo com Bakhtin (2009), ao conceber a relação entre linguagem, pensamento e práticas sociais no processo de construção do sujeito no mundo, reflete:

[...] o sentido de uma palavra é a soma de todos os eventos psicológicos que a palavra desperta em nossa consciência. É um todo complexo, fluido e dinâmico, que tem várias zonas de estabilidade desigual. O significado é apenas uma das zonas do sentido, a mais estável e precisa. Uma palavra adquire o seu sentido no contexto em que surge; em contextos diferentes, altera o seu sentido. O significado permanece estável ao longo de todas as alterações do sentido. O significado dicionarizado de uma palavra nada mais é do que uma pedra no edifício do sentido, não passa de uma potencialidade que se realiza de formas diversas na fala. (VYGOTSKY L., 1998, p. 181) 
Em diálogo com os autores, estende-se a discussão a partir da leitura de Alves; Gonçalves (2011, p. 108), que, apoiados na Teoria do Círculo de Bakhtin, teorizam sobre a constituição dos sentidos dentro das práticas discursivas, e acrescentam que: "as variações entre os sentidos potenciais de uma palavra-signo e os já instaurados e dicionarizados no decorrer da ação humana ocorrem, [...] entre tema e significação, os quais são aspectos inter-relacionados e interdependentes na constituição discursiva da realidade". Dito isso, a inserção no mundo da escrita é um marco divisor de águas na vida da criança, pois o aprender a ler significa o desvelamento de um mundo novo, cheio de desafios e energias que a instigam a ir além.

Esse adentramento muda sua condição humana, política e social, como ressalvado por Heráclito de Éfeso: "Ninguém entra num mesmo rio uma segunda vez, pois quando isso acontece já não se é o mesmo; assim como as águas, que já serão outras"; assim é a criança quando é despertada para a magia das letras, pode ter sua história dividida em pré e pós-aprendizagem da leitura e da escrita. Argumento fortalecido por Smolka (2008, p. 57) quando aponta que a linguagem "[...] é uma atividade criadora e constitutiva de conhecimento e, por isso mesmo, transformadora. Nesse sentido, a aquisição e o domínio da escrita como forma de linguagem acarretam uma crítica mudança em todo o desenvolvimento cultural da criança."

A subjetividade, como algo inerente a constituição do sujeito, está presente no processo de alfabetização e diz respeito aos aspectos simbólicos, afetivos e emocionais que se relacionam ao ato de aprender e à projeção social do homem, por meio da aquisição da linguagem. Benveniste (2005) aponta para o princípio da intersubjetividade humana, o qual considera que o homem não existe fora da linguagem, posto que esta seja condição básica de sua existência. A forma do "dizer", ou seja, a linguagem em movimento, em funcionamento operacional, revela a subjetividade e a alteridade em cada indivíduo, isto é, na etapa de alfabetização é preciso compreender os processos subjetivos que constituem o sujeito em interação na, pela e com a linguagem.

Ainda de acordo com o autor, "não atingimos nunca o homem separado da linguagem e não o vemos nunca inventando-a. [...] É um homem falando que encontramos no mundo, um homem falando com outro homem [...]" (2005, p. 285). autor afirma que a linguagem assegura ao indivíduo o status de sujeito, que se define 
a partir de sua produção linguística, falada ou escrita, e que a possibilidade de interação através da linguagem liberta o homem do plano individual, da solidão e o coloca no plano social e coletivo, de participação e reconhecimentos de si e do outro nas esferas comunicacionais, em face de que é "essa condição de diálogo é que é constitutiva da pessoa, pois implica em reciprocidade - que eu me torne tu na alocação daquele que por sua vez se designa por eu" (grifos do autor), complementa Benveniste (2005, p. 286), enriquecendo a discussão.

De posse da teoria proposta por Benveniste, é que se alude à alfabetização como forma de apropriação da língua, agregando seus valores históricos e culturais, por meio da leitura e da escrita formalizadas, adquirida através do processo institucionalizado da escola, que deve criar, estrategicamente, condições que impulsionem o desenvolvimento das habilidades de leitura e escrita.

O interior das práticas alfabetizadoras é entendido como o processo de mediação entre o simbólico, o abstrato e as condições reais de aprendizagem das crianças. A criança precisa ser inserida no universo da língua, de modo que a palavra, escrita ou falada, seja uma organização social, que lhe oferte sentidos e significados e lhe oriente na organização das práticas sociais das quais participa. As relações entre a linguagem erudita e a linguagem cotidiana devem ser postas dentro do conceito de língua e na esteira do ato de alfabetizar, uma vez que "a língua passa a integrar a vida através de enunciados concretos (que a realizam); é igualmente através de enunciados concretos que a vida entra na língua" (BAKHTIN, 2011, p. 265). Dessa forma, a alfabetização é o estabelecimento de uma sensível relação com o mundo.

Uma vez compreendida as relações entre alfabetização e subjetividade, construídas principalmente através das palavras, como formas de "dizer" que singularizam o sujeito no processo de aprendizagem, aponta-se especificamente para a leitura e a escrita como (in) fluxos de entremeio no processo de significação humana por meio da linguagem.

\section{Leitura e escrita: (in)fluxos de entremeio}

Antes de textualizar a questão, toma-se como matéria-prima valorativa, na conjectura tempo-espaço de aprendizagem da leitura e escrita, a sabedoria das 
palavras do poema abaixo (de autoria atribuída a CARI (27/10/2003); disponível em: < http://www.prof2000.pt/users/bejml/poemas_recebidos.htm >. Acesso em: 15 mai. 2017), que expressa o encantamento infantil inerente ao ato de ler o escrever. Leiase:

\author{
Hino ao Livro \\ (em forma de soneto)
}

Em cada livro há barcos navegando, Há sonhos d'outro mar feito d'esp'rança; Há mundos encantados de criança, Noites em alegre dia despertando;

Em cada livro há portos esperando Pelas loucuras que só o louco alcança; Há caminhos de voo e de mudança P'rós que d'olhos no Céu vão navegando.

O livro é um pacto de coragem, Um parto que da dor faz alegria, Uma ponte que aponta a outra margem;

O livro é passaporte p'ra viagem De quem na solidão quer companhia E anseia descobrir cada miragem!

CARI

$(27 / 10 / 2003)$

A verdade da poesia pode ser percebida na prática, através da emoção e desvelamento da criança no mundo da leitura e da escrita. As novidades que ora se apresentam, desafiam-na a transpor os limites do dito, a mesmice cotidiana, e assumir um lugar de protagonista na sua história. A leitura criativa e prazerosa insere-se como campo lugar de instrução e construção da identidade dos sujeitos. Seus impactos alcançam campos de desenvolvimento psicológico, emocional, cognitivo, afetivo e social da criança, interpenetra pelo consciente e chega ao inconsciente, possibilitando uma "mediação central entre indivíduo e mundo transformando-o e sendo transformada por ele" (PIAGET, 1953, p. 01).

Neste sentido, compartilha-se o pensamento de Freire (2011, p. 19), ao destacar que a "compreensão crítica do ato de ler não se esgota na decodificação pura da palavra escrita ou da linguagem escrita, mas se antecipa e se alonga na inteligência do mundo", ou seja, a leitura é um ato de interação com o contexto em que se vive, posto que "a leitura do mundo precede sempre a leitura da palavra e a leitura desta 
implica a continuidade da leitura daquele" (p. 19-20) e, assim, o ato de ler e escrever serve para conquistar, ampliar e construir seu lugar no mundo, por meio do uso crítico da palavra.

Através da leitura, "as pessoas procuram descobrir, cultivar e empregar seus supostos recursos interiores e transformar sua subjetividade" (RUDIGER, 1996, p. 11). Ler não é apenas uma decodificação dos signos linguísticos, mas significa o estabelecimento de uma ponte de sentidos e significados entre o simbólico e os fatos reais. A compreensão do objeto lido é alcançada do desejo de decifrar e interpretar o sentido das coisas e dos fenômenos sociais e de ampliar as percepções de mundo, de forma heterogênea. Por isso a leitura deve ser a etapa inicial para o desenvolvimento da escrita e para a construção de sentidos, como diria Sciliar (1995, p. 16): "[...] o ato de escrever é uma sequela do ato de ler. É preciso captar com os olhos as imagens das letras, guardá-las no reservatório que temos em nossa mente e utilizá-las para compor depois as nossas próprias palavras".

Assim, a escrita inscreve-se como resultado desta leitura. Só aprende-se a escrever escrevendo e lendo muito (GARCIA, 1995), ou seja, um fluxo contínuo de leitura é que garante a segurança e qualidade na escrita. Esta é uma atividade comunicativa que compreende etapas de planejamento, processos, operações e estratégias de organização da memória e do pensamento, que é posto na escrita, em situações concretas de comunicação e interação social.

A apropriação da escrita perpassa pela aquisição da base alfabética, de uma organização didática e pedagógica que ative os sentidos, as habilidades cognitivas e intelectuais, levando a criança a compreender os princípios internos de regulação e funcionamento da língua, estabelecendo uma relação de sentido entre som (fonema) e letra (grafema), como unidades interconexas de apresentação do pensamento.

A escrita produz a identidade de quem a escreve, requer conhecimentos prévios de mundo e funciona como elemento estruturante da sociedade. Neste sentido, Orlandi (1999, p. 8), destaca que "a escrita, numa sociedade de escrita, não é só um instrumento, ela é estruturante. Isso significa que ela é lugar de constituição de relações sociais, isto é, de relações que dão uma configuração específica à formação social e aos seus membros". Assim, através da escrita o autor imprime suas marcas de participação social autêntica e original. 
Quanto à leitura, esta é um processo pelo qual se compreende, também, a linguagem escrita; e, a partir disso, intervém tanto o texto (sua forma e conteúdo) quanto o leitor (suas expectativas e conhecimentos prévios). Portanto, para ler é necessário, ao mesmo tempo, manejar com destreza as habilidades de decodificação e distinguir, no texto, os objetivos, as ideias, as experiências prévias e mesmo a motivação; a leitura é um processo de (re) construção dos próprios sentidos do texto lido (SOLÉ, 1998). Para a autora, a leitura exige motivação, objetivos claros e estratégias, e requer do professor, no processo de formação de leitores, o exercício de apresentar, discutir e exercitar ações para a interpretação do texto e que despertem no aluno o gosto de ler.

Desse modo, é fundamental o investimento em práticas significativas de leitura, que levem o educando a interagir com diversos meios e recursos textuais, pois a leitura apresenta-se como uma ferramenta facilitadora do processo de formação do sujeito, nos aspectos sociais, cognitivo e culturais, visto que é através dela que se chega a uma situação concreta de aprendizagem. Oliveira (1998, p. 70-71) sobre isto, salienta:

Por isso, é de fundamental importância que, desde o início, a alfabetização se dê num contexto de interação pela [leitura e] escrita. Por razões idênticas, deveria ser banido da prática alfabetizadora todo e qualquer discurso (texto, frase, palavra, "exercício") que não esteja relacionado com a vida real ou o imaginário das crianças, ou em outras palavras, que não esteja por elas carregado de sentido. (OLIVEIRA A., 1998, p. 70-71)

A leitura é de fundamental importância no processo de ensino e aprendizagem da criança. Tanto aquela apresentada pela família, quanto pela escola, tem um caráter formativo e dialógico. Nesse entremeio, tanto as obras de ficção (da literatura), como os estudos científico, culturais e históricos, transmitidos pelas disciplinas que compõem o tradicional currículo das escolas, devem estar vinculados às práticas intencionais de leitura. Assim, um processo eficiente de alfabetização deve propiciar à criança 0 entendimento de que aprender a ler e escrever requer não apenas 0 conhecimento de uma variedade de conteúdos, mas o domínio e interação com estes, de maneira ampla e intencional, transformando as informações abstratas, encontradas em diferentes veículos informativos, em conhecimentos próprios, construídos pela análise, síntese e reflexão das ideias. 
É urgente, portanto, que a escola desenvolva atividades de leitura e de escrita, a partir de diversos gêneros textuais e situações no contexto escolar, de modo que se levem as crianças a refletir sobre as possibilidades do mundo da fantasia, do imaginário e do real. A escola deve promover encontros e relações diversas entre o educando e a leitura, através de desenvolvimento de projetos e ações pedagógicas intencionais; adotando, assim, uma nova concepção de ensino e aprendizagem, a qual se refletirá na formação de jovens leitores.

Essa pressuposição considera então, que leitura e escrita, relacionadas à questão da subjetividade intrínseca ao ser humano, situam-se no entremeio sujeito e o mundo, funcionando como formas de tomada de interação social e participação crítica na sociedade, por meio da anunciação da palavra e da leitura crítica e participativa no mundo.

\section{Subjetividade e ensino: um olhar para as práticas pedagógicas alfabetizadoras e as perspectivas de letramento}

A busca por melhores métodos de alfabetizar tem sido o grande desafio da educação nas últimas décadas. As pesquisas sobre as formas de aquisição da escrita têm se fundamentado em diversas abordagens (genéticas, sociais, culturais, ambientais). As teorias de Vygotsky, Piaget, Paulo Freire, entre tantos outros teóricos que defenderam uma tese sobre a questão da aprendizagem, têm alcançado relevantes resultados como, por exemplo, os métodos de aquisição da língua escrita, propostos por Emília Ferreiro e Ana Teberosky, na Psicogênese da Língua Escrita. As autoras defendem uma teoria baseada na epistemologia genética de Piaget, na qual consideram que as crianças passam por diferentes hipóteses - espontâneas e provisórias -, até elaborarem conhecimentos sobre a leitura e escrita e se apropriar de toda a complexidade da língua.

No campo dos estudos sobre alfabetização e letramento, desenvolvidos pioneiramente por Mary Kato em 1986, com a obra "No mundo da escrita: uma perspectiva psicolinguística", na qual a autora destaca que a língua culta é resultante do letramento; e que tem tido significativos desdobramentos em pesquisas de diversos pesquisadores (como Ângela Kleiman; Leda Verdiani Tfouni; Roxane Rojo; Magda 
Soares, entre outros); é possível o entendimento de que a alfabetização deixou de ser apenas uma absorção do código escrito, e passou a ser uma atitude processual, que possibilita ao educando ter contato com a representação da língua, agregar seus valores históricos e culturais (TFOUNI, 2010) trazidos de suas experiências de mundo e incorporar as relações sociais cotidianas, tem sido uma das principais questões que permeia o discurso de estudiosos da educação e da linguagem.

Orientados por esses princípios, o discurso dos educadores da atualidade, bem como as práticas pedagógicas resultantes de seus trabalhos em sala de aula, baseiase numa perspectiva de alfabetização e letramento, entendendo-os como processos concomitantes, em que "um suscita o outro, ambos se interpenetram e o resultado possui uma grande força de esclarecimento" (CANDIDO, 1995, p. 13), que contribui para a qualidade na formação dos sujeitos. A título de ilustração, Soares (2003, p. 03) explicita ainda melhor o assunto:

\begin{abstract}
Dissociar alfabetização e letramento é um equívoco porque, no quadro das atuais concepções psicológicas, linguísticas e psicolinguísticas de leitura e escrita, a entrada da criança (e também do adulto analfabeto) no mundo da escrita se dá simultaneamente por esses dois processos: pela aquisição do sistema convencional de escrita - a alfabetização, e pelo desenvolvimento de habilidades de uso desse sistema em atividades de leitura e escrita, nas práticas sociais que envolvem a língua escrita - o letramento. Não são processos independentes, mas interdependentes, e indissociáveis: a alfabetização se desenvolve no contexto de e por meio de práticas sociais de leitura e de escrita, isto é, através de atividades de letramento, e este, por sua vez, só pode desenvolver-se no contexto de e por meio da aprendizagem das relações fonema-grafema, isto é, em dependência da alfabetização. (SOARES M., 1998, p. 03)
\end{abstract}

Tal direcionamento contradiz um pensamento tradicional e dogmático, historicamente produzido na esfera escolar, em que as preocupações sobre o "como se ensina" prevaleciam sobre o "como se aprende a ler e escrever" (FERREIRO; TEBEROSKY, 1999); mas, atualmente, há um entendimento de que existe uma relação muito próxima entre letramento e escolarização, já que a escola exerce forte influência no acesso às práticas cognitivas de aprendizagem, e, portanto, "[...] cabe à escola mais do que alfabetizar e possibilitar a seus alunos o domínio de um código e, através desse, a convivência com a tradição literária: dela se espera a formação do leitor" (SARAIVA, 2001, p. 23).

Os aspectos subjetivos estão implícitos nas práticas de ensino a partir de dispositivos que possibilitam a apreensão dos conteúdos. A relação docente/discente/objeto cognoscível se dá a partir de uma esfera simbólica e 
referencial, na qual se estabelece uma relação de cumplicidade e identificação entre os envolvidos na ação e num "campo transferencial inconsciente", em que "é de fundamental importância a maneira pela qual o professor responderá a esse laço transferencial, para que o aluno consiga realizar essa passagem e liberar seus investimentos libidinais para o trabalho de aprender" (ALMEIDA, 2002, p. 99).

Neste entendimento, é essencial que o educador promova constantes diálogos, que permitam o entrelaçamento entre conteúdos didáticos e experiências culturais de mundo, fazendo com que as crianças construam suas próprias noções de leitura e escrita, levando em consideração os elementos de natureza social, cultural e cognitiva, que as tornam heterogêneas no modo de aprender, e por isso carecem de formas e tempos diversos para construir significados sobre o objeto do conhecimento; considerando que "[...] o próprio processo de aquisição também vai se dando numa sucessão de momentos discursivos, de interlocução, de interação" (SMOLKA, 2008, p. 29), e a alfabetização, portanto, "é um processo discursivo: a criança aprende a ouvir, a entender o outro pela leitura; aprende a falar, a dizer o que quer pela escrita" (p. 63).

As práticas pedagógicas na alfabetização devem possibilitar o equilíbrio entre o conhecimento institucionalizado e o pensamento operante cognitivo de cada criança, considerando as variáveis subjetivas que interferem no processo de aprender, partindo da premissa de que se vive em "[...] um mundo que não é mera subjetividade, nem pura objetividade" (NAJMANOVICH, 2001, p. 95), e assim acontece o processamento da informação transmitida pelo professor, recebida pela criança e transformada em aprendizado. Ela é um "sujeito complexo [que] vê a si mesmo construir o mundo, se vê unido ao mundo, pertencente a ele e com autonomia relativa, inseparável e ao mesmo tempo distinguível. [ocupando] [...] um lugar paradoxal: é ao mesmo tempo construído e construtor" (p. 94).

É preciso, pois, ter um olhar plural para o processo de ensino e aprendizagem na alfabetização, na organização das práticas pedagógicas, de forma que o caráter prático, objetivo e emergencial da escola não elimine as subjetividades das crianças; pois, que, alfabetizar-se é conhecer um novo mundo, pelas trilhas da palavra enunciada. 


\section{Para (não) concluir}

A pertinência do entendimento sobre os aspectos subjetivos interligados à alfabetização resvala-se na importância desta no processo de formação do indivíduo. Vive-se em um mundo marcado pela objetividade e pela praticidade nas relações humanas e nos processos de construção do conhecimento e, muitas vezes, a subjetividade inerente a esses fenômenos são relegadas a um segundo plano, e nisso há um comprometimento no desenvolvimento humano, que deve ocorrer de forma saudável e equilibrada. $\mathrm{Na}$ fase de alfabetização, os prejuízos dessa mecanização podem representar um distanciamento irreparável entre a escola (intermediada pela figura do professor) e a criança.

A compreensão da subjetividade como aspecto que emana da essência humana, que por isso não pode ser desvinculada do homem, favorece o desenvolvimento de práticas pedagógicas que promovam as habilidades de leitura e escrita da criança.

As teorias que embasaram este estudo contribuem para o entendimento da linguagem, escrita e falada, como elementos identitários, e que esse entendimento seja partilhado nas práticas pedagógicas dos professores alfabetizadores, os quais devem trabalhar numa perspectiva de letramento, promovendo dinâmicas centralizadas nas formas como cada criança assimila o conhecimento, tornando-as críticas e independentes intelectualmente.

Portanto, um olhar subjetivo para a alfabetização, permite compreendê-la como etapa básica e fundamental na formação do indivíduo, o qual tem, na apropriação do conhecimento, uma forma de constituir-se como sujeito. Perceber os meandros e as interfaces que conjugam os processos subjetivos inerentes à criança é agregar valores conceituais e atitudinais para a melhoria das práticas de ensino.

\section{REFERÊNCIAS}

ALMEIDA, S. F. C. de. Psicanálise e educação: revendo algumas observações e hipóteses a respeito de uma (im) possível conexão. In: KUPFER, M. C.; LAJONQUIÈRE, L. (Orgs.). Psicanálise infância educação. Anais do III Colóquio do LEPSI. São Paulo: USP, 2002. p. 95-106.

ALVES, B. F.; GONÇALVES, J. B. C. A constituição dos sentidos da palavra lúdico em documentos oficiais da educação brasileira: relações dialógicas em nível de significação e tema. In: COSTA, Maria de Fátima Vasconcelos; ATEM Érica. 
ALTERidade: o outro como problema. Fortaleza: Expressão Gráfica e Editora Ltda, 2011. p. 107-121.

BAKHTIN, M. Estética da criação verbal. 6. ed. São Paulo: Martins Fontes, 2011. Marxismo e filosofia da linguagem. 13. ed. São Paulo: Hucitec, 2004.

BENVENISTE, E. Da subjetividade na linguagem. In: Problemas de linguística geral I. 5. ed. São Paulo: Pontes, 2005.

Problemas de linguística geral II. 2. ed. São Paulo: Pontes, 2006.

CANDIDO, A. O direito à literatura. In: Vários escritos. São Paulo: Duas Cidades, 1995.

FERREIRO, E. e TEBEROSKY, A. Psicogênese da língua escrita. Porto Alegre: Artmed, 1999.

FREIRE, P. A importância do ato de ler: em três artigos que se completam. 51. ed. São Paulo: Cortez, 2011.

GARCIA, R. Cartas Londrinas e de outros lugares sobre o lugar da educação. Rio de Janeiro: Relume Dumará, 1995.

GONZÁLEZ REY, F. Sujeito e subjetividade: uma aproximação histórico-cultural. São Paulo: Pioneira Thomson Learning, 2003.

JONHSON, R. A.; RUHL, J. M. Viver a vida não vivida: a arte de lidar com os sonhos não realizados e cumprir o seu propósito na segunda metade da vida. Petrópolis: Vozes, 2010.

KATO, M. No mundo da escrita: uma perspectiva psicolinguística. São Paulo: Ática, 1986.

LACERDA, C. B. F. de. Inter-relação entre oralidade, desenho e escrita: o processo de construção do conhecimento. São Paulo: Cabral, 1995.

LAJONQUIÈRE, L de. Figuras do infantil: a psicanálise na vida cotidiana com as crianças. Petrópolis: Vozes, 2010.

NAJMANOVICH, D. O sujeito encarnado. Rio de Janeiro: DP\&A, 2001.

ORLANDI, E. P. Reflexões sobre Escrita, Educação Indígena e Sociedade. In: Escritos: Escrita, Escritura, Cidade (I), №. 5. Campinas: LABEURB, 1999, p. 7-22.

OLIVEIRA, A. M. M. A formação de professores alfabetizadores: lições da prática. In: GARCIA, R. L. Alfabetização dos alunos das classes populares. São Paulo: Cortez, 1998. p. 69-87. 
PIAGET, J. A relação entre a afetividade e inteligência do desenvolvimento mental em crianças. Boletim de Psicologia, no 12, p.01, 1953.

POEMAS RECEBIDOS. Poema 'Hino ao Livro', de CARI (27/10/2003). Disponível em: <http://www.prof2000.pt/users/bejml/poemas_recebidos.htm>. Acesso em: 15 mai. 2017.

RUDIGER, F. R. Literatura de autoajuda e individualismo: contribuições ao estudo da subjetividade na cultura de massa contemporânea. Porto Alegre: Ed. UFRGS, 1996.

SANTIAGO, A. L. A inibição intelectual na psicanálise. Rio de janeiro: Jorge Zahar, 2005.

SARAIVA, J. A. (Org.). Literatura e alfabetização: do plano do choro ao plano da ação. Porto Alegre: Artmed, 2001.

SCILIAR, M. In: Blau - Jornal bimestral de literatura, Porto Alegre, n. 5, agosto de 1995.

SOARES, M. Alfabetização e letramento. 6. ed. São Paulo: Contexto, 2011.

- Letramento e alfabetização: as muitas facetas. 26a Reunião Anual da Anped. - GT Alfabetização, Leitura e Escrita. Poços de Caldas, 7 de outubro de 2003.

SOLÉ, I. Estratégias de leitura. 6. ed. Porto Alegre: Artmed, 1998.

SMOLKA, A. L. B. A criança na fase inicial da escrita: a alfabetização como processo discursivo. 12. ed. São Paulo: Cortez, 2008.

TFOUNI, L. V. Letramento e alfabetização. São Paulo: Cortez, 2010.

VYGOTSKY, L. S. Pensamento e linguagem. São Paulo: Martins Fontes, 2000. 